\title{
Stroke in type 2 diabetes mellitus patients admitted to emergency unit in Central African country (Congo): Preliminary findings
}

\author{
Bertrand Fikahem Ellenga-Mbolla ${ }^{1,2 \#}$, Henri Germain Monabeka ${ }^{2}$, Paul Macaire Ossou-Nguiet ${ }^{2}$, \\ Gilbert Fabrice Otiobanda ${ }^{3}$, Kryste Chancel Mahoungou Guimbi ${ }^{3}$, Thierry Raoul Gombet ${ }^{2,4}$, \\ Suzy-Gisèle Kimbally-Kaky ${ }^{1,2}$, Benjamin Longo Mbenza ${ }^{5}$
}

\footnotetext{
${ }^{1}$ Department of Cardiology, University Hospital of Brazzaville, Brazzaville, Congo;

\#Corresponding Author: ellenga bertrand@hotmail.com

${ }^{2}$ Department of Medicine, Faculty of Health Sciences, Marien Ngouabi University, Brazzaville, Congo

${ }^{3}$ Intensive Care Unit, University Hospital of Brazzaville, Brazzaville, Congo

${ }^{4}$ Emergengy Unit, University Hospital of Brazzaville, Brazzaville, Congo

${ }^{5}$ Faculty of Health Sciences, Walter Sisulu University, Mthatha, South Africa
}

Received 5 October 2013; revised 2 November 2013; accepted 9 November 2013

Copyright (C) 2013 Bertrand Fikahem Ellenga-Mbolla et al. This is an open access article distributed under the Creative Commons Attribution License, which permits unrestricted use, distribution, and reproduction in any medium, provided the original work is properly cited.

\section{ABSTRACT}

Background: The cardiovascular risk factors including type 2 diabetes mellitus (T2DM) are a public health problem in sub-Saharan Africa. The aim of this study is to determine the prevalence and factors associated with stroke in T2DM patients admitted to the emergency Unit in Brazzaville. Patients and Methods: This is the preliminary findings of a cross-sectional study including patients with T2DM, admitted in Emergency Unit of University Hospital of Brazzaville from January to April 2011. One hundred and seven patients were included. Sex ratio was 1.5. Results: The mean age was $60.3 \pm 10.2$ years (range $\mathbf{4 0}-\mathbf{8 0}$ years). Stroke story was noted in 5 cases $(4.6 \%)$. The main pathologies were metabolic complications $(n=51 ; 47.6 \%)$ and cardiovascular diseases $(n=36 ; 33.6 \%)$, dominated by stroke (17 cases). Epidemiological factors associated with stroke were high standard living (OR $=3,95 \% \mathrm{Cl}: 1.02-8.9, \mathrm{p}=0.03)$, polypharmacy (OR $=3.7,95 \% \mathrm{Cl}: 1.27-10.8, p=0.01$ ), previous hospitalization (OR $=3.1,95 \% \mathrm{Cl}: 1.07-8.9, \mathrm{p}=$ 0.03 ), and the absence of antiplatelet therapy (OR $=4.2,95 \% \mathrm{Cl} 1.2$ to $15, \mathrm{p}=0.03)$. Clinical associated factors were coma (OR $=3.3,95 \% \mathrm{Cl}$ 1.14 to $9.6, p=0.02)$ and the presence of severe hypertension (OR = 4, 95\% Cl: 1.2 - 12, $\mathrm{p}=0.02)$.

${ }^{*}$ Competing interests: None.
Finally, prognostic factors were the transfer in intensive care unit (OR $=9.8,95 \% \mathrm{Cl}: 2.7-34, p<$ 0.001). Conclusion: The first cardiovascular complication in patients with T2DM admitted in emergency at University Hospital of Brazzaville is stroke. Primary prevention in high-risk patients is still inadequate.

Keywords: Type 2 Diabetes Mellitus; Stroke; Emergency; Brazzaville

\section{INTRODUCTION}

The type 2 diabetes mellitus (T2DM) is a public health problem in sub-Saharan Africa (SSA) where its prevalence constantly increases and the complications of this disease become concerned [1]. The stroke represents a serious and frequent complication of T2DM because of its lethality, disability and relapse [2]. T2DM patient often has multiple risk factors, which lead to frequent occurrence of cardiovascular complications [1]. Thus, a comprehensive and efficient management of T2DM patients, includes the management of all risk factors. Several predictors of stroke have been described in black patient with T2DM. Among them, there is an increase in blood pressure, presence of infection, poor medical care, the addictions and occurrence of microvascular complications [3]. In SSA, the management of T2DM is difficult because of poverty, poor access to medical care, lack of equipment and qualified healthcare professionals [4, 
5].

The aim of this study is to determine the prevalence and factors associated with stroke in T2DM patients admitted to the emergency Unit in Brazzaville.

\section{PATIENTS AND METHODS}

It is a cross-sectional study, conducted from January to April 2011 (4 months) in the emergency Unit of University Hospital of Brazzaville.

We included all patients admitted with a diagnosis of T2DM, with records including at least of standard boilogy, an electrocardiogram and chest X-ray. A CT scan performed within 48 hours was required for the diagnosis of stroke.

\subsection{Variables Analyzed}

They were epidemiological (age, sex, anthropometry, diabetes follow up, duration of diabetes, clinical history, outpatient treatment, adherence and reference), clinical (signs and diagnosis) and prognostic (transfer in intensive care unit and death).

\subsection{Definitions}

Obesity was defined as a body mass index greater than $30 \mathrm{~kg} / \mathrm{m}^{2}$. Polypharmacy was seen when taking more than three medications in outpatient treatment. Poor compliance was indicated by irregular intake of treatment. Reference represented patients addressed by a secondary health center. The high standard of living was based on occupation and monthly salary. Major hyperglycemia was defined when glycemia $\geq 5 \mathrm{~g} / \mathrm{L}$. Severe hypertension was defined when blood pressure $\geq 180 / 110$ $\mathrm{mm} \mathrm{Hg}$.

\subsection{Statistical Analysis}

Data were treated with EPI INFO 3.3.2 software (CDC Atlanta, USA) and SPSS 10.0 for Windows (Chocago, IL, USA). Quantitative variables were expressed as mean and standard deviation, and qualitative staffing percentage. The chi-square test was used to compare qualitative variable and ANOVA for quantitative variable. The univariate risk of stroke was assessed in calculating Odds ratio (OR) with $95 \%$ confidence intervals $(95 \% \mathrm{CI})$. Multivariates analyses such as logistic regression models were used to assess the independent determinants of stroke. The receiving operating characteristic (ROC) curve to predict stroke was plotted. The significance level was 0.05 .

\section{RESULTS}

One hundred and seven patients were included. They were 65 women $(60.7 \%)$, the sex ratio was 1.5 . The mean age was $60.3 \pm 10.2$ years (range 40 and 80 years). The mean age by sex was $60.4 \pm 9.8$ years (range: $40-78$ years) for women and $60.3 \pm 11$ years (range: $40-80$ years) for men $(\mathrm{p}=0.98)$. In ROC curve (Figure 1), age $>62.5$ ans to predict stroke (sensitivity $64.7 \%$, specificity $57.8 \%$ ) was no significant.

\subsection{Epidemiological Status}

High standard living was noted in 45 cases (42\%), including 22 women (33.8\%) and 23 men (54.8\%). Patients were referred from a secondary health center in 26 cases (24.3\%). The mean duration of T2DM was $7.6 \pm 5.4$ years (range $0-22$ years), respectively $5 \pm 7.7$ years (range 0 - 2 years) for women and $7.6 \pm 6$ years (range 0 - 22 years $)$ for men $(p=0.6)$. Duration of diabetes $>10.5$ years in ROC curve (Figure 1) was predicted stroke with sensibility $35.3 \%$ and specificity $74.4 \%(\mathrm{p}=0.048)$. The history of diabetes was known in 96 cases $(90 \%)$, respectively 59 cases $(90.8 \%)$ for women and $37(88 \%)$ for men. Previous hospitalization was noted in 33 cases $(30.8 \%)$. The distribution of patients by sex, duration of diabetes, poor adherence, polypharmacy and the number of medications is reported in Table 1.

Diabetes treatment included an oral antidiabetic alone in 63 cases $(58.9 \%)$, insulin alone in 16 cases $(15 \%)$ and both associated in 10 cases $(9.3 \%)$. There wasn't diabetes treatment in 18 cases $(16.8 \%)$.

A history of stroke was noted in 5 cases $(4.6 \%)$. The antiplatelet therapy was ongoing in 13 patients $(12.1 \%)$.

\subsection{Clinical Features}

The clinical signs presented by patients on admission are reported in Table 2.

Seventeen cases of cerebral ischemia divided in 16 constituted strokes and one transient ischemic attack

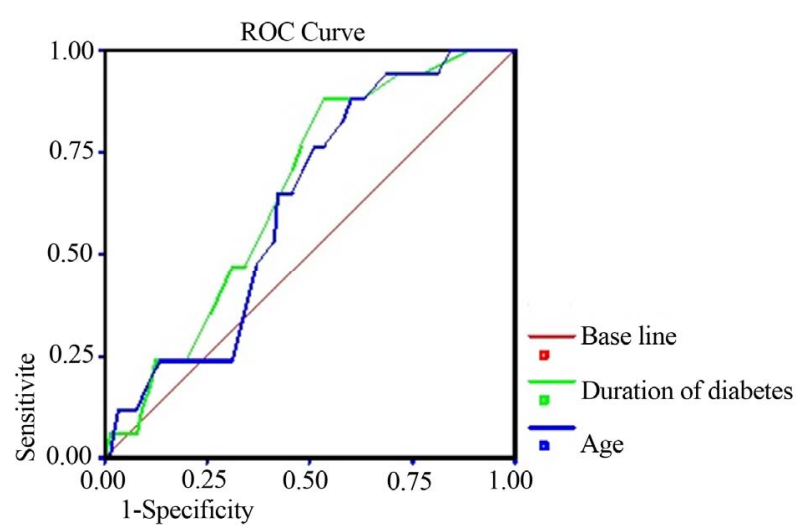

Figure 1. ROC curve of age and duration of diabetes to predict stroke. For age, area under curve $(\mathrm{AUC})=0.622(95 \% \mathrm{CI}$ : $0.497-0.747 ; \mathrm{p}=0.112)$. For duration of diabetes $\mathrm{AUC}=$ 0.652 (95\% CI: $0.538-0.774)$. 
Table 1. Sex distribution, monitoring of diabetes, poor adherence, polypharmacy, and the number of drugs being.

\begin{tabular}{|c|c|c|c|}
\hline & Females $(\mathrm{n}=65)$ & Males $(\mathrm{n}=42$ & All $(\mathrm{n}=107)$ \\
\hline \multicolumn{4}{|l|}{ Diabetes monitoring } \\
\hline Although monitoring & $26(40)$ & $12(28.6)$ & $38(35.5)$ \\
\hline Poorly monitored & $33(50.8)$ & $24(57.1)$ & $57(53.3)$ \\
\hline Not followed & $6(9.2)$ & $6(14.3)$ & $12(11.2)$ \\
\hline Poor compliance & $26(40)$ & $15(35.7)$ & $41(38.3)$ \\
\hline \multicolumn{4}{|l|}{ Drug } \\
\hline None & $4(6.2)$ & $7(16.7)$ & $11(10.3)$ \\
\hline 1 & $24(36.9)$ & $14(33.3)$ & $38(35.5)$ \\
\hline 2 & $15(23.1)$ & $9(21.4)$ & $24(22.4)$ \\
\hline Polypharmacy & $23(35.4)$ & $12(28.6)$ & $35(32.7)$ \\
\hline
\end{tabular}

Table 2. Clinical signs listed in the admission of patients.

\begin{tabular}{ccc}
\hline & $\mathrm{n}$ & $\%$ \\
\hline Major hyperglycemia & 45 & 42.1 \\
Coma & 37 & 34.6 \\
Polyuri polydipsia signs & 32 & 30 \\
Fever & 26 & 24.3 \\
Dyspnea & 23 & 21.5 \\
Severe hypertension & 17 & 15.8 \\
Dehydration & 17 & 15.8 \\
Hemiplegia & 15 & 14 \\
Cough & 13 & 12.1 \\
Psychomotor agitation & 12 & 11.2 \\
State of shock & 10 & 9.3 \\
Convulsions & 10 & 9.3 \\
Hypoglycemia & 10 & 9.3 \\
Vomiting & 7 & 6.5 \\
Abdominal pain & 7 & 6.5 \\
Brief loss of consciousness & 6 & 5.6 \\
Heart rhythm disorders & 5 & 4.6 \\
Aphasia & 3 & 2.8 \\
\hline
\end{tabular}

were registered. It represents the first condition beyond those attributable to glycemic control (major hyperglycemia and hypoglycemia). All patients with cerebral ischemia were hypertensive $(\mathrm{p}<0.0001)$ and were know diabetics $(\mathrm{p}=0.06)$. The mean age of patients with stroke was $64.2 \pm 7.8$ years vs $59.6 \pm 10.5$ for other patients (p $=0.09$ ). The mean duration of diabetes in patients with stroke was $9.7 \pm 4.8$ years vs $7.2 \pm 5.4$ years for other ( $p$ $=0.04)$. Diabetes follow up was regular in patients with stroke in 12 cases $(70.6 \%)$ vs. 26 cases $(28.9 \%)$ for others $(\mathrm{p}<0.01)$.

The distribution of the main diseases is reported in Table 3.

Table 4 shows univariates Odds of stroke. Any vari-
Table 3. Synopsis of pathologies.

\begin{tabular}{ccc}
\hline & $n$ & $\%$ \\
\hline Metabolic Complications & $\mathbf{5 1}$ & $\mathbf{4 7 . 6}$ \\
Decompensation of diabetes & 28 & 26.2 \\
Diabetic coma & 16 & $\mathbf{1 5}$ \\
Hypoglycemia & 7 & 6.5 \\
Cardiovascular disease & $\mathbf{3 6}$ & $\mathbf{3 3 . 6}$ \\
Stroke and transcient ischemic attack & 17 & 15.8 \\
Hypertensive encephalopathy & $\mathbf{1 1}$ & 10.3 \\
Heart failure & 6 & 5.6 \\
Arteriopathy & 1 & 0.9 \\
Infectious diseases & $\mathbf{2 6}$ & $\mathbf{2 8}$ \\
Bronchopulmonary infection & 8 & 7.5 \\
Diabetic foot & 7 & 6.5 \\
Gastrointestinal infection & 5 & 4.7 \\
Urinary tractus infection & 2 & 1.9 \\
Septicemia & 2 & 1.9 \\
Myositis & 1 & 0.9 \\
Erysipelas & 1 & 0.9 \\
Other & $\mathbf{1}$ & $\mathbf{0 . 9}$ \\
Uremic syndrome & 1 & 0.9 \\
\hline
\end{tabular}

able was independent determinant of stroke in logistic regression (Table 5). In ROC curve, only polypharmacy (Figure 2) was significant to predict stroke: sensitivity $58.8 \%$, specificity $72.2 \%(\mathrm{p}=0.043)$.

The average duration in emergency unit was $32.5 \pm 20$ hours (range 12 to 96 hours). This duration was $47.4 \pm$ 23.5 hours for patient with stroke vs $29.6 \pm 18.5$ hours for others $(\mathrm{p}<0.001)$. A treatment in Intensive care Unit of University Hospital of Brazzaville was required in 13 cases $(12.1 \%)$. Three cases of deaths were recorded (2.8\%), including 2 cases of stroke (OR 11.8, 95\% CI 1.01 to $139, \mathrm{p}=0.03)$.

\section{DISCUSSION}

\subsection{Study Limitations}

The study we conducted in an emergency unit, we were able to raise the profile of T2DM and other risk factors. It's a preliminary finding. The best would be to conduct a cohort study to determine the long-term prognosis. Indeed, glucose and blood pressure levels, recurrent stroke, readmissions and mortality are important to assess the real risk of morbidity and mortality. In addition, we had included the outcome of patients after orientation in intensive care unit or department of diabetology.

\subsection{Epidemiological Aspects}

The profile of our patients reflects the socio-demographic and epidemiological realities in SSA. Indeed, the low standard of living (58\%), poor reference $(24.3 \%)$, 
Table 4. Univariates factors associated with stroke.

\begin{tabular}{|c|c|c|c|c|c|}
\hline & Stroke $(\mathrm{n}=17)$ & Without stroke $(n=90)$ & OR & $95 \%$ IC & p-value \\
\hline \multicolumn{6}{|l|}{ Epidemiological aspects } \\
\hline Female & $12(70.6)$ & $53(58.9)$ & 1.67 & $0.54-5.1$ & 0.26 \\
\hline Age $>75$ years & $3(17.6)$ & $9(10)$ & 1.92 & $0.46-8$ & 0.19 \\
\hline High standard of living & $11(64.7)$ & $34(37.8)$ & 3.01 & $1.02-8.9$ & 0.03 \\
\hline Polypharmacy & $10(58.8)$ & $25(27.8)$ & 3.7 & $1.27-10.8$ & 0.01 \\
\hline History of stroke & $2(11.8)$ & $3(3.3)$ & 3.86 & $0.59-25$ & 0.1 \\
\hline Anterior hospitalization & $9(52.9)$ & $24(26.7)$ & 3.09 & $1.07-8.9$ & 0.03 \\
\hline Without antiplatelet & $5(29.4)$ & $8(8.9)$ & 4.2 & $1.2-15$ & 0.03 \\
\hline Poor compliance & $5(29.4)$ & $36(40)$ & 0.6 & $0.2-1.9$ & 0.29 \\
\hline \multicolumn{6}{|l|}{ Clinical aspects } \\
\hline Obesity & $16(94.1)$ & $70(77.8)$ & 4.5 & $0.5-36$ & 0.06 \\
\hline Severe hypertension & $6(35.3)$ & $11(12.2)$ & 4 & $1.2-12$ & 0.02 \\
\hline Coma & $10(58.8)$ & $27(30)$ & 3.3 & $1.14-9.6$ & 0.02 \\
\hline Major hyperglycemia & $3(17.6)$ & $42(46.7)$ & 0.24 & $0.06-0.91$ & 0.01 \\
\hline \multicolumn{6}{|l|}{ Prognosis } \\
\hline Transfer in intensive care unit & $7(41.2)$ & $6(6.7)$ & 9.8 & $2.7-34$ & $<0.001$ \\
\hline
\end{tabular}

Table 5. Independents determinants of stroke by logistic regression.

\begin{tabular}{cccccc}
\hline Independant variables & $\beta$ coefficient & Standard error & Wald $\mathrm{X}^{2}$ & OR $(95 \% \mathrm{CI})$ & $\mathrm{p}$-value \\
\hline Age (years) & 0.026 & 0.047 & 0.559 & $1.02(0.93-1.12)$ & 0.575 \\
Age $>$ 75 years (yes vs no) & -0.274 & 1.418 & -0.382 & $0.58(0.03-9)$ & 0.701 \\
Duration of diabetes & 0.042 & 0.081 & 0.519 & $1.04(0.88-1.22)$ & 0.603 \\
Anterior hospitalization (yes/no) & 1.138 & 0.92 & 1.237 & $3.12(0.51-19)$ & 0.216 \\
Coma (yes vs no) & 2.069 & 1.159 & 1.784 & $7.92(0.81-76)$ & 0.074 \\
Major glycemia (yes vs no) & -14.59 & 253.8 & -0.05 & $<0.01\left(0->10^{5}\right)$ & 0.954 \\
Severe hypertension (yes vs no) & 1.001 & 0.842 & 1.188 & $2.72(0.52-14)$ & 0.234 \\
HSL (yes vs no) & 1.247 & 0.777 & 1.605 & $3.48(0.75-15)$ & 0.108 \\
Obesity (yes vs no) & 1.27 & 1.229 & 1.033 & $3.56(0.32-39)$ & 0.301 \\
Polypharmacy (yes vs no) & 0.734 & 0.855 & 0.858 & $2.08(0.38-11)$ & 0.39 \\
Transfert intensive care (yes/no) & 14.23 & 253.8 & 0.056 & $>10^{5}\left(<10^{5}->10^{5}\right)$ & 0.955 \\
Sex (male vs female) & -1.464 & 0.875 & -1.672 & $0.23(0.04-1.28)$ & 0.094 \\
\hline
\end{tabular}

HSL: High standard of living.

poor adherence $(64.5 \%)$, demonstrate the realities of management of cardiovascular disease in our environment [6].

Among metabolic complications, glycemic imbalance was found in $51.4 \%$ of cases and $42.1 \%$ of major hyperglycemia. It is recognized that the major hyperglycemia is pejorative in the acute stage of cardiovascular complications of T2DM [7]. It plays also a role in the early development of complications [8]. The specificity of this major hyperglycemia in the black people is the presence of ketosis, thus defining the ketosis prone T2DM [1,9]. The others complications is represented by hypoglycemia $(9.3 \%)$. It is often secondary to poor adherence to treatment, but also the low status and illiteracy [6].

Associated pathologies, we identified cardiovascular disease with stroke in the foreground and infectious diseases. There were mainly represented by the bronchopulmonary infections and diabetic foot. The diabetic foot is often mixed in our context with a tricky treatment, sometimes leading to amputation in $20 \%$ of cases according to Longo-Mbenza et al. [10] and 43\% reported by Monabeka et al. [11].

\subsection{Stroke}

Cardiovascular complications were mainly represented by stroke $(15.8 \%)$ and hypertensive encephalopathy $(10.3 \%)$. Any studied factor was independent determinant of stroke in our study. Many factors were commonly independently associated with ischemic stroke in T2DM patients [12]. Arboix et al., identified hypertension, atrial 


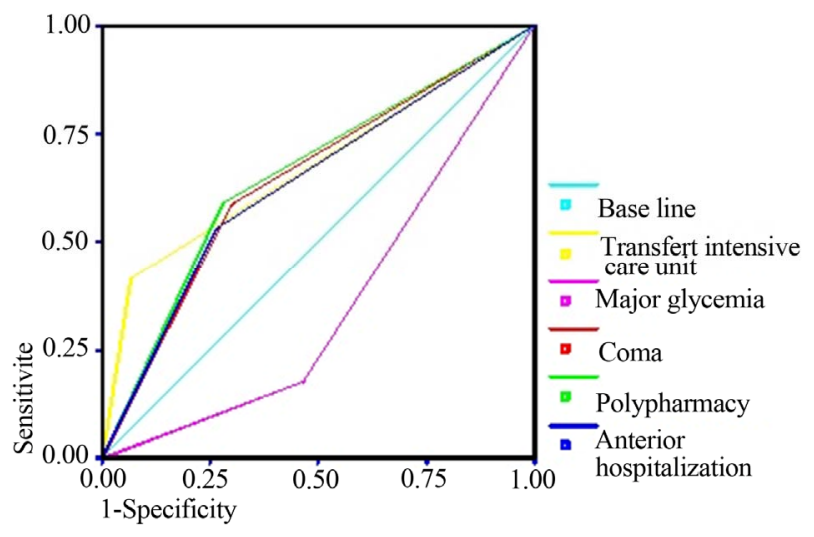

Figure 2. ROC curve to predict stroke for polypharmacy (AUC $=0.655 ; 95 \%$ CI: $0.508-0.803)$ Coma $(\mathrm{AUC}=0.644 ; 95 \% \mathrm{CI}$ : $0.497-0.791 ; \mathrm{p}=0.06)$ severe hypertension $(\mathrm{AUC}=0.615$; 95\% CI: $0.457-0.774 ; \mathrm{p}=0.133)$ anterior hospitalization $(\mathrm{AUC}=0.631 ; 95 \% \mathrm{CI}: 0.481-0.782 ; \mathrm{p}=0.07)$.

fibrillation, congestive heart failure, and valvumopathy was causes of stroke [12]. The female sex was significantly associated with stroke and mortality [12]. This aspect was not significant in our study. According to Mbanya et al., the prevalence of cardiovascular complications varies from 4 to 28 in diabetes, and $15 \%$ of patients with stroke have diabetes, and $5 \%$ of diabetes develop stroke [1]. In our series, the number of stroke appears to be limited, because we included only patients who had realized the CT brain scan. However, in Brazzaville, $50 \%$ of hypertensive emergencies are represented by stroke [13]. The diagnosis of stroke remains difficult in SSA. Indeed, the lack of equipment and qualified healthcare professionals limit the diagnosis and management [5]. It is certain that the achievement of CT scan improves the initial emergency treatment and prognosis [14]. The poor glycemic control in patients contributes to the early onset of complications including stroke [8], and alters the prognosis [7] what motivated the transfer resuscitation in a large number in our series. In addition, the social level of patients limit access to care [6]. In our series, stroke is univariate factor of mortality in T2DM patients. In addition, stroke is the leading cause of cardiovascular emergencies at University Hospital of Brazzaville [15]. Given these aspects, primary prevention using the lifestyle measures involving diet and physical activity reduces the risk of occurrence of complications especially stroke $[16,17]$. In primary prevention, the occurrence of diabetes is significantly lower in subjects with regular physical activity in addition to appropriate $\operatorname{diet}[16]$.

\section{CONCLUSION}

The risk of stroke is higher in T2DM. Given the difficulties of management of cardiovascular risk factors in sub-Saharan Africa, an active primary prevention would not only lessen the cost of treatment, but also reduce the occurrence of complications.

\section{ACKNOWLEDGEMENTS}

We thank Dr Charley Elenga Bongo for his contribution in the manuscript translation.

\section{REFERENCES}

[1] Mbanya, J.C., Motala, A.A., Sobngwi, E., Assah, F.K. and Enoru, S.T. (2010) Diabetes in sub-Saharan Africa. Lancet, 375, 2254-2266.

http://dx.doi.org/10.1016/S0140-6736(10)60550-8

[2] Sagui, E. (2007) Stroke in sub Saharan Africa. Médecine Tropicale, 67, 596-600.

[3] Longo-Mbenza, B., Mombo Ngimbi, R., Vangu Ngoma, D., Mbungu Fuele, S. and Buassa-bu-Tsumbu, B. (2008) Risk factors of stroke in blacks congolese patients with type 2 diabetes mellitus. Annales de Cardiologie et d'Angéologie, 57, 37-43.

[4] Gning, S.B., Thiam, M., Fall, F., Ba-Fall, K., Mbaye, P.S. and Fourcade L. (2007) Diabetes mellitus in sub Saharan Africa: Epidemiological aspects and management issues. Médecine Tropicale, 67, 607-611.

[5] Chin, J.H. (2012) Stroke in Sub-Saharan Africa: An urgent call for prevention. Neurology, 78, 1007. http://dx.doi.org/10.1212/WNL.0b013e318248df95

[6] Gombet, T.R., Ellenga Mbolla, B.F., Ikama, M.S., Ekoba, J. and Kimbally-Kaky G. (2009) Cost of emergency cardiovascular care at the university hospital center in Brazzaville, Congo. Médecine Tropicale, 69, 45-47.

[7] Longo-Mbenza, B., Lelo Tshinkwela, M. and Mbuilu Pukuta, J. (2008) Rates and predictors of stroke-associated case fatality in Black Central African Patients. Cardiovascular journal of Africa, 19, 72-76.

[8] Tuei, V.C., Maiyoh, G.K. and Ha, C.E. (2010) Type 2 diabetes mellitus and obesity in sub-Saharan Africa. Diabetes and Metabolic Research and Review, 26, 433-445. http://dx.doi.org/10.1002/dmrr.1106

[9] Djrolo, Fr., Amoussou-Guenou, D., Wanvoegbe, A. and Glitho, S. (2011) Diabète sucré à tendance cétosique à Cotonou. Louvain Médical, 130, 97-98.

[10] Longo Mbenza, B., Ndungo Kidinda, F., Buassa-BuTsumbu, B., Mbungu Fuele, S. and Vunga Ngoma, D. (2009) Epidemiological and clinical profil of diabetic foot in General Hospital of Kinshasa. Médecine d'Afrique Noire, 56, 401-409.

[11] Monabeka, H.G. and Nsakala Kibangou, N. (2001) Epidemiological and clinical aspects of diabetic foot (CHU Brazzaville). Bulletin de la Société de Pathologie Exotique, 94, 246-248.

[12] Arboix, A., Milian, M., Oliveres, M., Garcia-Eroles, L. and Massons, J. (2006) Impact of female gender on prognosis in type 2 diabetic patients with ischemic stroke. European Neurology, 56, 6-12. http://dx.doi.org/10.1159/000094249

[13] Ellenga Mbolla, B.F., Gombet, T.R., Mahoungou Guimbi, 
K.C., Otiobanda, G.F., Ikama, M.S., Kimbally-Kaky, G. and Etitiele, F. (2011) Hypertensives emergencies in University hospital of Brazzaville (Congo). Médecine Tropicale, 71, 97-98.

[14] Ossou-Nguiet, P.M., Otiobanda, G.F., Obondzo Aloba, K., Ellenga Mbolla, B.F., Bandzouzi-Damba, B. and Makosso, E. (2013) Contribution of CT scan on epidemiology and management of stroke in a Central African country. International Journal of Stroke, 8, E27. http://dx.doi.org/10.1111/ijs.12118

[15] Gombet, Th., Ellenga Mbolla, B.F., Ikama, M.S., Okiemy,
G. and Etitiele, F. (2007) Cardiovascular emergencies at Teaching Hospital of Brazzaville. Médecine d'Afrique Noire, 54, 505-511.

[16] Lloyd, C.E. and Barnett, A.H. (2008) Physical activity and risk of diabetes. Lancet, 371, 5-6. http://dx.doi.org/10.1016/S0140-6736(08)60044-6

[17] Feigin, V.L. and Krishnamurthi, R. (2011) Stroke prevention in the developing world. Stroke, 42, 3655-3658. http://dx.doi.org/10.1161/STROKEAHA.110.596858 